\begin{tabular}{|c|c|}
\hline Title & $\begin{array}{l}\text { Effect of Copper Pretreatment on the Zincate Process and Subsequent Copper Electrodeposition of AZ31 Magnesium } \\
\text { Alloy }\end{array}$ \\
\hline Author(s) & T ang, Jinwei; A zumi, Kazuhisa \\
\hline Citation & $\begin{array}{l}\text { Journal of the Electrochemical Society, 158(9), D535-D540 } \\
\text { https://doi.org/10.1149/1.3607426 }\end{array}$ \\
\hline Issue Date & $2011-06-29$ \\
\hline Doc URL & http:/hdl. handle.net/2115/46930 \\
\hline Rights & $\begin{array}{l}\text { () The Electrochemical Society, Inc. 2011. All rights reserved. Except as provided under U.S. copyright law, this work } \\
\text { may not be reproduced, resold, distributed, or modified without the express permission of The Electrochemical Society } \\
\text { (ECS). The archival version of this work was published in J. Electrochem. Soc., 158(9), pp. D535-D540 (2011) }\end{array}$ \\
\hline Type & article \\
\hline File Information & JES158-9_D535-D540.pdf \\
\hline
\end{tabular}

Instructions for use 


\section{Effect of Copper Pretreatment on the Zincate Process and Subsequent Copper Electrodeposition of AZ31 Magnesium Alloy}

Jinwei Tang ${ }^{\mathrm{z}}$ and Kazuhisa Azumi*

Graduate School of Engineering, Hokkaido University, Kitaku, Sapporo 060-8628, Japan

A small amount of $\mathrm{Cu}^{2+}$ ions was added to the activation bath used for pretreatment of the plating process of an AZ31 Mg alloy. In the activation process, a small amount of $\mathrm{Cu}$ was deposited at high density on the substrate surface accompanying $\mathrm{Mg}$ dissolution $(\mathrm{Cu}$ pretreatment). These $\mathrm{Cu}$ deposits acted as nucleation seeds for $\mathrm{Zn}$ deposition in the following zincate process and provided a uniform and dense $\mathrm{Zn}$ layer almost completely covering the substrate. The Cu layer electroplated on this zincated substrate showed considerable improvement in density and uniformity compared with those of the sample without $\mathrm{Cu}$ pretreatment. Crosssectional SEM observation revealed that a less-defective interface between the $\mathrm{Cu}$ layer and substrate was obtained for the $\mathrm{Cu}$-prepared sample. This structure also contributed to the improvement of adhesion strength. The mechanism of this improvement was investigated using electrochemical measurement and scanning electron microscopy observation with energy dispersive X-ray spectroscopy analysis.

(C) 2011 The Electrochemical Society. [DOI: 10.1149/1.3607426] All rights reserved.

Manuscript submitted January 31, 2011; revised manuscript received April 22, 2011. Published June 29, 2011.

Owing to their superior strength, light weight and rich natural resources, $\mathrm{Mg}$ and its alloys are attractive materials in various applications. Unfortunately, the surface of $\mathrm{Mg}$ is easily covered with a thick oxide or hydroxide layer with a high electric resistance, which may not be suitable for some applications such as electronic devices. Therefore, it is important to establish a plating method that can produce functional coatings on $\mathrm{Mg}$ alloys such as corrosion-resistant and electrically conductive coatings with sufficient adhesivity.

Since a thick passivation film is formed on $\mathrm{Mg}$ under an ambient atmosphere, pretreatment is necessary to remove the surface layer and to suppress its reformation prior to the plating process. ${ }^{1-5}$ It is also important to obtain a uniform surface condition on $\mathrm{Mg}$ alloys for plating because intermetallic compounds such as $\mathrm{Mg}_{\mathrm{x}} \mathrm{Al}_{\mathrm{y}}$ are formed at grain boundaries. Despite these difficulties, electroplating can provide potentially uniform coatings with good corrosion resistance for Mg alloys by using zincate pretreatment. ${ }^{6-11}$ Application of zincate pretreatment to $\mathrm{Mg}$ alloys, however, has sometimes resulted in non-uniform $\mathrm{Zn}$ deposition, probably due to non-uniform dissolution of the substrate during the zincate process. ${ }^{11}$ In the case of $\mathrm{Al}$ and its alloys, zincate pretreatment has also been optimized to obtain uniform $\mathrm{Zn}$ deposition. The effectiveness of various methods for reducing the influence of intermetallic compounds of $\mathrm{Al}$ alloys in an electroless plating process has been studied. These methods include etching treatment, ${ }^{12}$ formation of a seed layer by using a dry process, ${ }^{13-17}$ and other techniques. Our group previously reported that addition of a small amount of $\mathrm{Cu}$ ions to the etching bath can dramatically improve the uniformity of $\mathrm{Zn}$ deposits on Al-Si alloys in the double zincate process because $\mathrm{Cu}$ deposits formed in the etching process acted as nucleation seeds for $\mathrm{Zn}$ deposition $\mathrm{C \textrm {Cu }}$ pretreatment). ${ }^{18}$ Since $\mathrm{Cu}$ pretreatment was effective for obtaining uniform $\mathrm{Zn}$ deposits on $\mathrm{Al}$ alloys, it was worth considering a similar method for zincate pretreatment of $\mathrm{Mg}$ alloys. Therefore, in this work, a $\mathrm{Cu}$ pretreatment was developed for an $\mathrm{Mg}$ alloy. For the $\mathrm{Cu}$ pretreatment an $\mathrm{Mg}$ alloy is immersed in an activation bath containing a low concentration of $\mathrm{Cu}^{2+}$ ions before the zincate process. The processes concerning with $\mathrm{Cu}^{2+}$ ions is proposed as followings. In this activation process, $\mathrm{Mg}$ dissolution and $\mathrm{Cu}$ deposition proceed as a substitution reaction. Fine $\mathrm{Cu}$ particles are deposited densely and uniformly, and there is little growth of the particles at the low concentration of $\mathrm{Cu}^{2+}$ ions in the activation bath. The $\mathrm{Cu}$ particles then act as nucleation sites for $\mathrm{Zn}$ deposition in the following zincate process. As a result, $\mathrm{Zn}$ is deposited densely and uniformly on the substrate to provide a suitable zincated surface for plating. In this study, the effect of $\mathrm{Cu}$ pretreatment on the zincate process of an AZ31 Mg alloy was investigated using scanning electron micros-

\footnotetext{
* Electrochemical Society Active Member.

z E-mail: tangjw@eng.hokudai.ac.jp
}

copy and electrochemical measurements. $\mathrm{Cu}$ was then electrodeposited on an AZ31 Mg alloy in an alkaline plating bath to examine the effect of $\mathrm{Cu}$ pretreatment on adhesion strength of the $\mathrm{Cu}$ plating layer. All processes used in this work were conducted under mild conditions using baths that did not contain any toxic chemicals.

\section{Experimental}

Specimens were prepared from a die-cast AZ31 Mg alloy sheet composed of 3.19 wt $\% \mathrm{Al}, 0.81$ wt $\% \mathrm{Zn}, 0.334$ wt $\% \mathrm{Mn}$, and bal. $\mathrm{Mg}$. The testing specimens were cut into rectangular pieces of $10 \times 10 \times 7$ or $30 \times 30 \times 7 \mathrm{~mm}$ in size. The specimens were embedded in epoxy resin, and the exposed area of 100 or $900 \mathrm{~mm}^{2}$ was mechanically polished with $\mathrm{SiC}$ papers of 700, 1000, and 1500 grits. They were then cleaned with distilled water and dried with a stream of air. Bath compositions and operation conditions of the processes used in this study are shown in Table I. Milli-Q filtered water and analytical-grade chemicals were used for preparation of all baths. Specimens were subjected to a pickling bath, an activation bath with (Cu-prepared) or without (non-prepared) $\mathrm{Cu}^{2+}$ ions, and then a zincate bath, successively. Specimens were washed with distilled water after each treatment and immersed immediately in the next bath to avoid drying. A potentio/galvanostat (Ivium Technologies, model IviumStat) was employed for $\mathrm{Cu}$ electrodeposition by using a typical three-electrode system consisting of a working electrode (WE) of $\mathrm{AZ31} \mathrm{Mg}$ alloy, an $\mathrm{Ag} / \mathrm{AgCl}$ reference electrode (RE) and a counter electrode (CE) of a Cu plate $(99.99 \%)$. In this paper, electrode potential is presented as a value vs. $\mathrm{Ag} / \mathrm{AgCl}-\mathrm{RE}$. $\mathrm{Cu}$ was electrodeposited in an alkaline plating bath with current density of $-12 \mathrm{~mA} \mathrm{~cm}^{-2}$ under a stirring condition. All experiments were conducted at room temperature. Adhesion strength of the $\mathrm{Cu}$ electroplating layer to the substrate was measured by using a pull-off adhesion tester (Elcometer 106). Scanning electron microscopy (SEM) combined with energy dispersive X-ray spectroscopy (EDX, EDXS) (JEOL Co., model no. JSM-6500F) was used to observe the surface morphology and elemental composition of the coatings.

\section{Results and Discussion}

$\mathrm{Cu}$ pretreatment and zincate process. - In order to investigate the effects of $\mathrm{Cu}^{2+}$ ions in the activation process, SEM images were taken for samples immersed in the activation bath with or without $\mathrm{Cu}^{2+}$ ions as shown in Fig. 1. After the pickling process, the substrate surface was smooth as shown in Fig. 1a. The sample after activation in the bath without $\mathrm{Cu}^{2+}$ ions had a non-uniform film composed of $\mathrm{Mg}$ hydroxide and $\mathrm{Mg}$ fluoride on the surface as a dark area shown in Fig. 1b. In this activation process, an $\mathrm{Mg}$ hydroxide film that was formed through rinsing in distilled water after the pickling process was dissolved in the following reaction 


\begin{tabular}{|c|c|c|c|}
\hline Process & $\begin{array}{c}\text { Bath } \\
\text { composition }\end{array}$ & $\begin{array}{l}\text { Concentration } \\
\left(\mathrm{g} \mathrm{l}^{-1}\right)\end{array}$ & Condition \\
\hline Degrease & Ethanol & - & $\begin{array}{c}\text { Rinse or } \\
\text { ultrasonication }\end{array}$ \\
\hline Pickling & $\mathrm{HF}+\mathrm{HCl}$ & $\begin{array}{c}0.25 \text { wt } \% \\
\text { each }\end{array}$ & $\begin{array}{c}\text { Room } \\
\text { temp., } 20 \mathrm{~s}\end{array}$ \\
\hline \multirow[t]{4}{*}{ Activation } & $\mathrm{K}_{4} \mathrm{P}_{2} \mathrm{O}_{7}$ & 86 & $\begin{array}{c}\text { Room } \\
\text { temp., } 120 \mathrm{~s}\end{array}$ \\
\hline & $\mathrm{Na}_{2} \mathrm{CO}_{3}$ & 15 & \\
\hline & $\mathrm{KF}$ & 4.5 & \\
\hline & $\mathrm{CuSO}_{4} \cdot 5 \mathrm{H}_{2} \mathrm{O}$ & 0 or 0.08 & \\
\hline \multirow[t]{3}{*}{$\begin{array}{l}\text { Zincate } \\
\text { pretreatment }\end{array}$} & $\mathrm{ZnSO}_{4} \cdot 7 \mathrm{H}_{2} \mathrm{O}$ & 46 & pH 10.4 \\
\hline & $\mathrm{K}_{4} \mathrm{P}_{2} \mathrm{O}_{7}$ & 139 & $\begin{array}{c}\text { Room } \\
\text { temp., } 1000 \mathrm{~s}\end{array}$ \\
\hline & $\begin{array}{c}\mathrm{Na}_{2} \mathrm{CO}_{3} \\
\mathrm{KF}\end{array}$ & $\begin{array}{l}5 \\
6\end{array}$ & \\
\hline \multirow[t]{4}{*}{$\begin{array}{l}\mathrm{Cu} \\
\quad \text { electrodeposition }\end{array}$} & $\mathrm{CuSO}_{4} \cdot 5 \mathrm{H}_{2} \mathrm{O}$ & 70 & $p \mathrm{H} 13.5$ \\
\hline & $\mathrm{KNaC}_{4} \mathrm{H}_{4} \mathrm{O}_{6} \cdot 4 \mathrm{H}_{2} \mathrm{O}$ & 346 & $\begin{array}{l}\text { Stirring at } \\
600 \mathrm{rpm}\end{array}$ \\
\hline & $\mathrm{NaOH}$ & 120 & Room temp. \\
\hline & $\mathrm{H}_{3} \mathrm{BO}_{3}$ & 20 & $\begin{array}{r}I_{\mathrm{C}}=-12 \mathrm{~mA} \\
\mathrm{~cm}^{-2} 3600 \mathrm{~s}\end{array}$ \\
\hline
\end{tabular}

Dissolution of the $\mathrm{Mg}$ substrate and then formation and successive dissolution of a new Mg hydroxide film occurred. In this activation bath, a less-soluble Mg fluoride film that might suppress further dissolution of the substrate was also formed. ${ }^{9}$ The surface therefore showed a patchwork pattern of corrosion and protected areas as seen in Fig. 1b.

On the other hand, a quite uniform surface was obtained for the $\mathrm{Cu}$-prepared sample as shown in Fig. 1c. Probably, $\mathrm{Cu}$ was deposited on the substrate after removal or thinning of the initial hydroxide film in reaction 1 and acted as charge transfer sites to accelerate the substrate dissolution as discussed below. Fast dissolution of $\mathrm{Mg}$ prevented accumulation of $\mathrm{Mg}$ hydroxide on the surface and thus provided a smooth and uniform surface condition as shown in Fig. 1c. Although the $\mathrm{Cu}$ deposits could not be detected by EDS analysis because of its small deposition mass, they acted as efficient catalysts

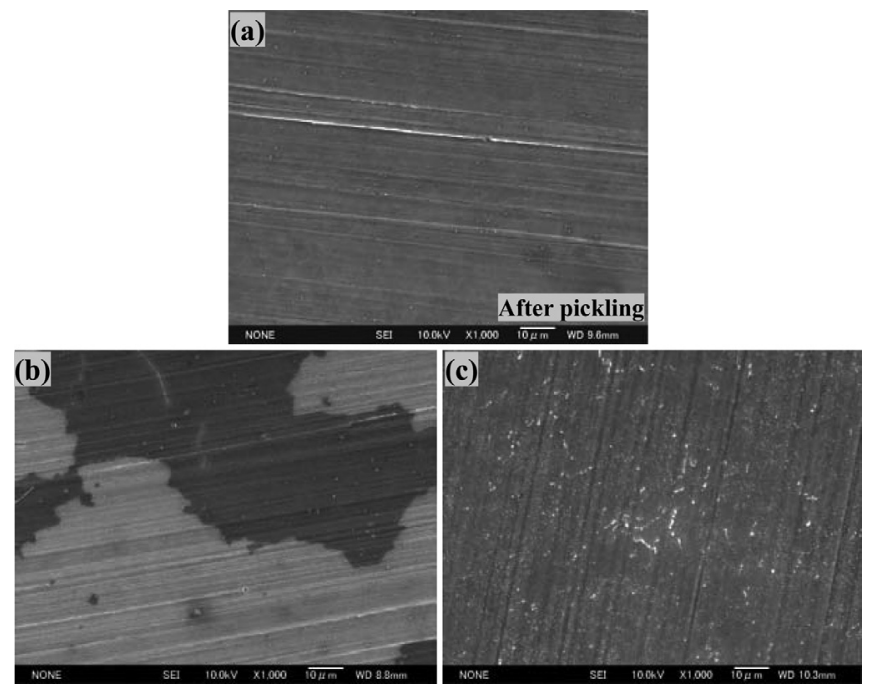

Figure 1. SEM images of the AZ31 Mg alloy after pickling treatment (a) and after activation in solutions without (b) and with (c) $\mathrm{Cu}^{2+}$ ions.

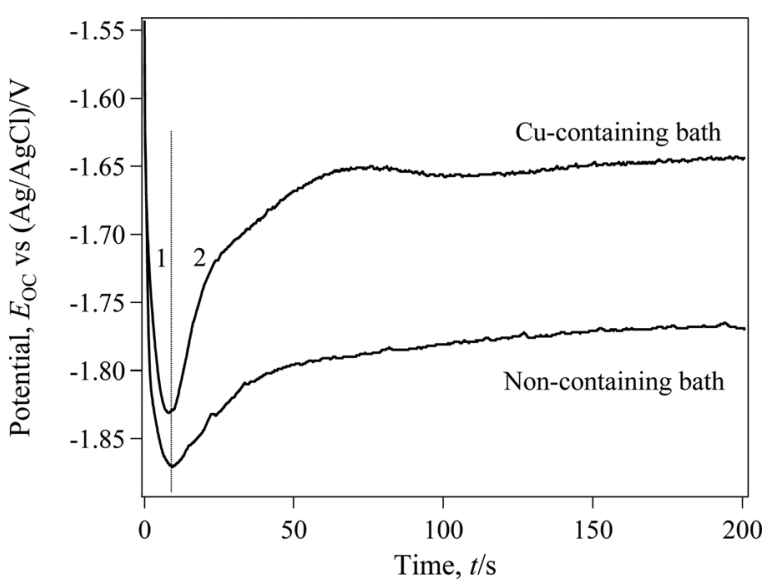

Figure 2. Change in $\mathrm{EOC}, E_{\mathrm{OC}}$, of the $\mathrm{AZ} 31 \mathrm{Mg}$ alloy during the activation process in baths with and without $\mathrm{Cu}^{2+}$ ions.

for electrochemical reaction on the substrate, resulting in a dramatic effect on surface conditioning.

The open circuit potential, $E_{\mathrm{OC}}$, of the specimens immersed in the activation baths with and without $\mathrm{Cu}^{2+}$ ions is shown in Fig. 2 . The curve measured for the non-prepared sample can be divided into two stages. The steep drop of $E_{\mathrm{OC}}$ within $10 \mathrm{~s}$ in the first stage suggests rapid dissolution of the hydroxide film described by reaction 1 and initiation of the dissolution reaction of the Mg substrate. The shift of $E_{\mathrm{OC}}$ in the noble direction and successive slow transition to a steady potential in the second stage is mainly attributed to the process of surface covering with $\mathrm{Mg}$ hydroxide and $\mathrm{Mg}$ fluoride films as mentioned above. Although these films suppressed the dissolution reaction of the substrate, $E_{\mathrm{OC}}$ remained less-noble due to continuous dissolution of the $\mathrm{Mg}$ substrate and low charge transfer efficiency via these films.

On the other hand, $E_{\mathrm{OC}}$ of the Cu-prepared sample shows noble potential compared with that of the non-prepared sample. The difference between the two curves can be explained by the model illustrated in Fig. 3. In the activation bath, dissolution of the surface
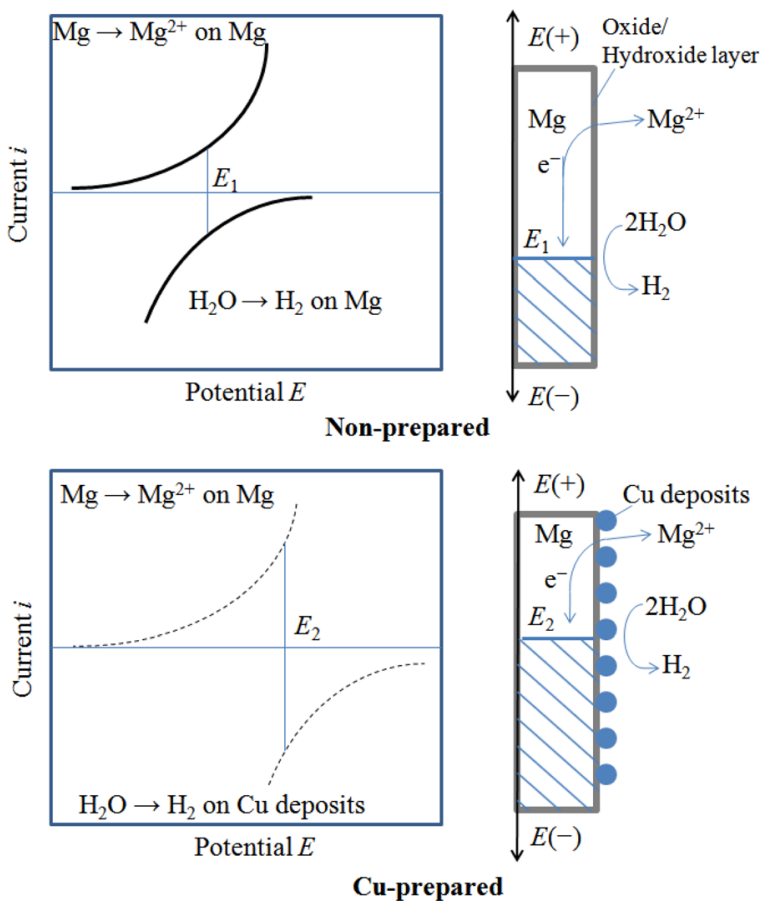

Figure 3. (Color online) Schematic representation of mixed potential of the AZ31 Mg alloy during the activation process $\left(E_{1}\right)$ and Cu preparation process $\left(E_{2}\right)$. 
hydroxide film promotes oxidation of the $\mathrm{Mg}$ substrate to form an oxide/hydroxide film and dissolution of $\mathrm{Mg}$ through the film. This oxidation process leaves electrons in the electrode to cause a shift of $E_{\mathrm{OC}}$ in the less-noble direction and promotes $\mathrm{H}_{2}$ gas evolution. A considerably less-noble $E_{\mathrm{OC}}$ in a steady state at about $-1.8 \mathrm{~V}$ in the activation bath without $\mathrm{Cu}^{2+}$ ions indicates a less-active surface of the specimen for $\mathrm{H}_{2}$ gas evolution reaction. $\mathrm{Mg}$ is a base metal and its surface is easily oxidized to be covered with a thick hydroxide layer in aqueous solution, which disturbs electron transfer and combination of adsorped $\mathrm{H}$ atoms to form $\mathrm{H}_{2}$ molecules. On the other hand, in the activation bath containing $\mathrm{Cu}^{2+}$ ions, decrease of $E_{\mathrm{OC}}$ causes not only $\mathrm{H}_{2}$ gas evolution but also $\mathrm{Cu}$ deposition on the substrate. Since the electrochemical activity of $\mathrm{Cu}$ is considerably higher than that of $\mathrm{Mg}$, a small amount of $\mathrm{Cu}$ deposition on the $\mathrm{Mg}$ substrate greatly increases the efficiency of $\mathrm{H}_{2}$ gas evolution, even at smaller overpotential. A relatively noble $E_{\mathrm{OC}}$ also accelerates dissolution of the $\mathrm{Mg}$ substrate. As a result, $\mathrm{H}_{2}$ gas evolution and $\mathrm{Mg}$ dissolution become noticeable in the activation bath containing $\mathrm{Cu}^{2+}$ ions.

In order to investigate the effect of $\mathrm{Cu}$ pretreatment on $\mathrm{Zn}$ deposition in the zincate process, SEM images were taken for samples at different zincating times as shown in Fig. 4. From these images, it is clear that the zincate process was initiated with nucleation followed by growth of $\mathrm{Zn}$ deposits. For example, the non-prepared sample after 30-s immersion shows initiation of $\mathrm{Zn}$ nucleation on the surface as seen in Fig. 4a. It is also observed that nucleation occurred preferentially at the grain boundary of the substrate as shown by an arrow. After $300 \mathrm{~s}$, the $\mathrm{Zn}$ particles increased in number and size and were deposited preferentially on the grain boundary as shown in Fig. 4b. After $1000 \mathrm{~s}, \mathrm{Zn}$ particles grew continuously and became connected to each other as seen in Fig. 4c. However, the $\mathrm{Zn}$ layer did not completely cover the substrate, probably due to the low density of the initial nucleation and rather slow deposition rate of $\mathrm{Zn}$, which enabled growth of individual $\mathrm{Zn}$ particles.
A considerable number of $\mathrm{Zn}$ particles were observed on the $\mathrm{Cu}-$ prepared sample after zincating for $30 \mathrm{~s}$ as shown in Fig. 4d. After $300 \mathrm{~s}$, all Zn particles had grown and the density of Zn particles was considerably higher than that of the non-prepared sample as can be seen from a comparison of Fig. 4e with Fig. 4b. After 1000 s, a compact and dense $\mathrm{Zn}$ layer almost completely covered the substrate as shown in Fig. 4f. Although Zn was deposited along the grain boundary, further $\mathrm{Zn}$ deposition proceeded on the whole surface. This improvement in $\mathrm{Zn}$ deposition is possibly due to the formation of dense $\mathrm{Cu}$ seeds on the substrate, and these $\mathrm{Cu}$ seeds act as a catalyst for $\mathrm{Zn}$ deposition, leading to rapid and dense $\mathrm{Zn}$ deposition. This mechanism will be further discussed later.

The effect of $\mathrm{Cu}$ pretreatment on formation of a $\mathrm{Zn}$ layer was also confirmed by the time-transition of open circuit potential, $E_{\mathrm{OC}}$, during the zincate process as shown in Fig. 5. In these traces, initial drop of $E_{\mathrm{OC}}$ corresponds to rapid dissolution of the substrate, and the following increase in $E_{\mathrm{OC}}$ and successive slow approach to a steady potential at ca. $-1.3 \mathrm{~V}$ corresponds to $\mathrm{Zn}$ deposition and completion of the zincate process. The steady potential was slightly less noble than the EOC of a $\mathrm{Zn}$ plate at $-1.25 \mathrm{~V}$ measured in the same bath. This indicates that dissolution reaction of the Mg substrate continues slowly beneath the $\mathrm{Zn}$ deposits, especially in the case of a non-prepared sample, or that EOC of the zincate layer differs slightly from that of a $\mathrm{Zn}$ plate. The noticeable difference between the non-prepared sample and the $\mathrm{Cu}$-prepared sample is the noble $E_{\mathrm{OC}}$ and faster $\mathrm{Zn}$ deposition process for the latter, which can be attributed to the catalytic function of $\mathrm{Cu}$ seeds for substitution reaction of $\mathrm{Mg}$ dissolution and $\mathrm{Zn}$ deposition. Electrons formed by the $\mathrm{Mg}$ dissolution reaction transfer efficiently to $\mathrm{Zn}^{2+}$ ions via $\mathrm{Cu}$ seeds, resulting in noble $E_{\mathrm{OC}}$ which promoted $\mathrm{Mg}$ dissolution and thus rapid $\mathrm{Zn}$ deposition on $\mathrm{Cu}$ seeds with high density. In conclusion, a small amount of $\mathrm{Cu}$ deposits not only increases the deposition rate but also improves uniformity of $\mathrm{Zn}$ deposits on an AZ31 Mg alloy.
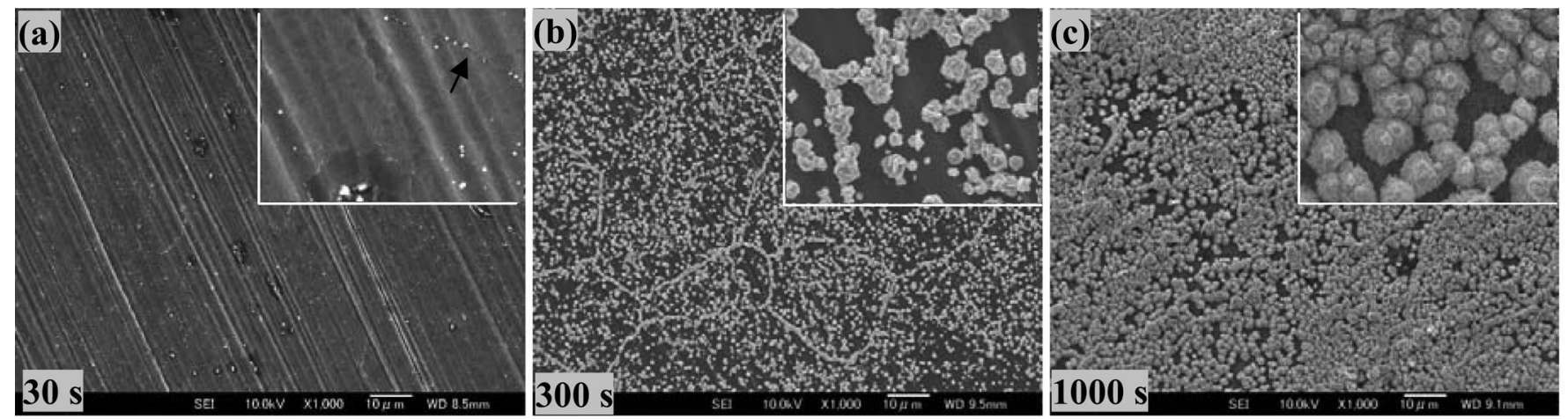

Non-prepared
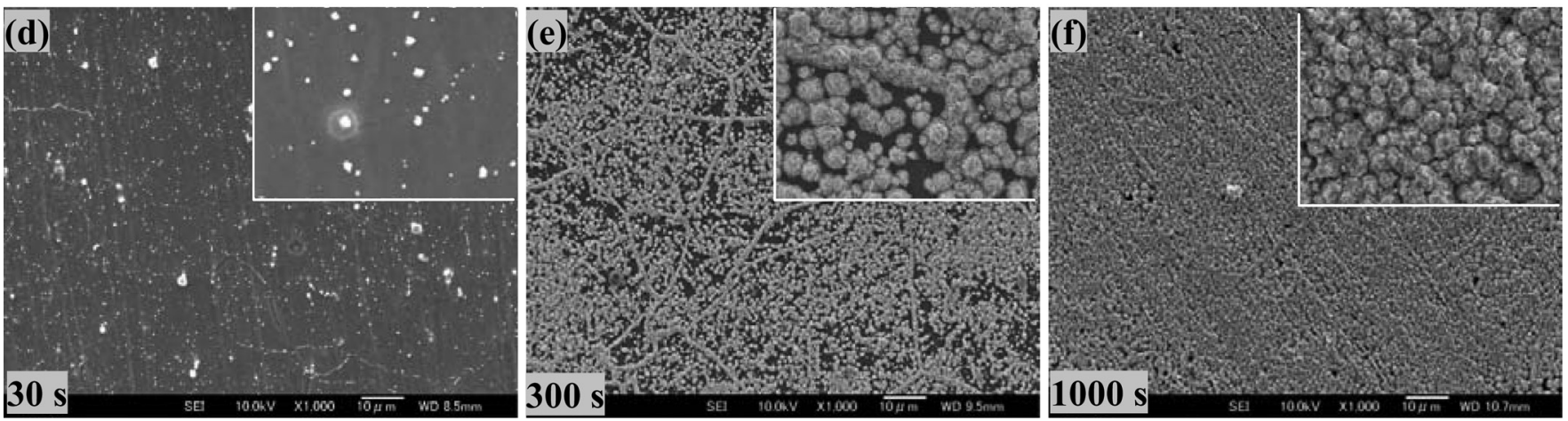

$\mathrm{Cu}$-prepared

Figure 4. SEM images of non-prepared (a,b,c) and Cu-prepared (d,e,f) AZ31 Mg alloy samples after zincate pretreatment for different times. Magnified $(\times 5)$ images of each surface are superimposed at the upper-right in each image. 


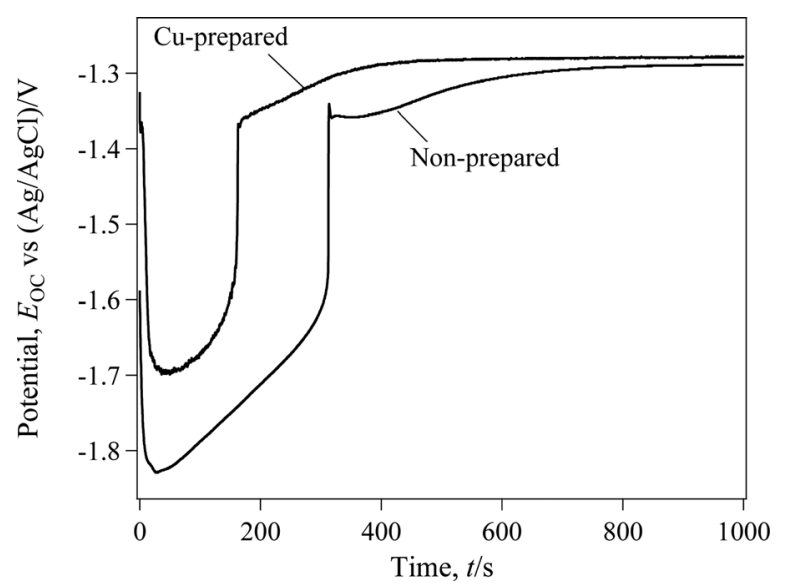

Figure 5. Changes in EOC, $E_{\mathrm{OC}}$, of non-prepared and Cu-prepared AZ31 $\mathrm{Mg}$ alloy samples during the zincate process.
Electrodeposition of copper.-In order to investigate the effect of $\mathrm{Cu}$ pretreatment on the plating process, $\mathrm{Cu}$ was electrodeposited on samples prepared with and without $\mathrm{Cu}$ pretreatment and the surfaces of the $\mathrm{Cu}$ layers were observed by using SEM as shown in Fig. 6. From these images, it is evident that the morphology of the $\mathrm{Cu}$ layer was strongly influenced by $\mathrm{Cu}$ pretreatment. For example, undulation of the surface of the $\mathrm{Cu}$ layer formed on the non-prepared sample shown in Fig. 6a reflects the morphology of Zn deposits shown in Fig. 4c. Defects on the $\mathrm{Cu}$ layer surface shown by arrows are thought to be induced by non-uniform deposition of the $\mathrm{Zn}$ layer on the substrate. The cross-sectional SEM image shown in Fig. 6c also indicates the existence of defects between the $\mathrm{Cu}$ layer and substrate and voids in the $\mathrm{Cu}$ layer. Results of EDS line analysis shown in Fig. 6e reflect such a structure, i.e., the $\mathrm{Zn}$ signal was distributed at the interface between the $\mathrm{Cu}$ layer and substrate and the $\mathrm{Cu}$ signal gradually increased from the $\mathrm{Zn}$ layer to a steady value of the $\mathrm{Cu}$ layer. This indicates that some of the substrate was not covered with the $\mathrm{Zn}$ layer as seen in Fig. $4 \mathrm{c}$ and that $\mathrm{Cu}$ expanded to this area from $\mathrm{Cu}$ deposits at the initial stage of $\mathrm{Cu}$ electrodeposition. This process caused formation of voids at the interface and lessened the adhesion strength of the plating layer as discussed later.

\section{Non-prepared}
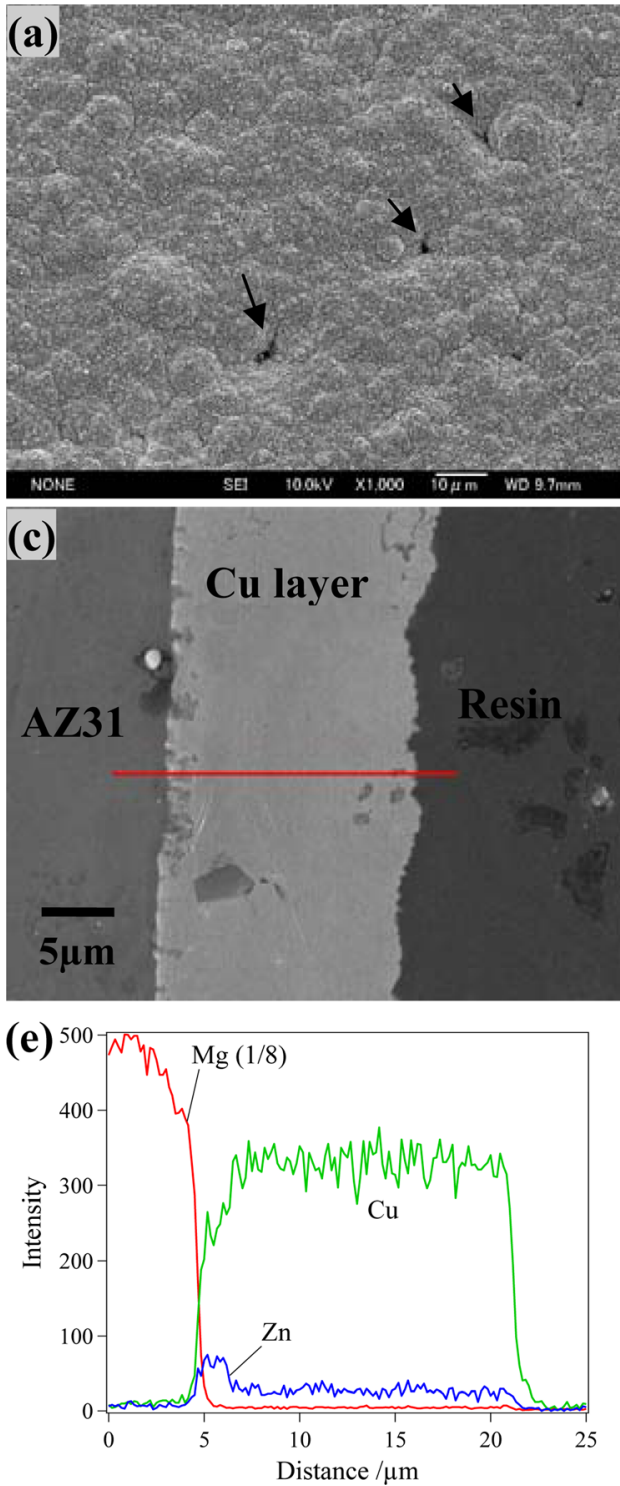

\section{$\mathrm{Cu}$-prepared}
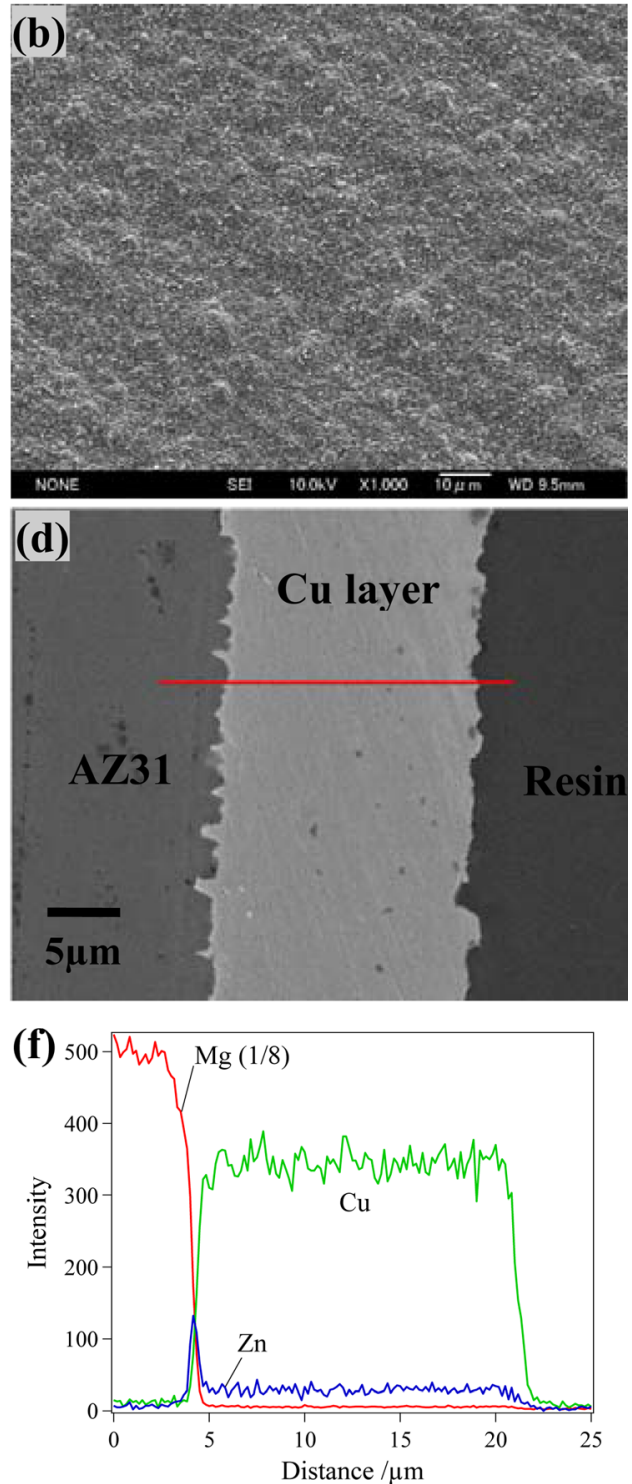

Figure 6. (Color online) SEM images of non-prepared $(\mathrm{a}, \mathrm{c})$ and $\mathrm{Cu}-$ prepared $(\mathrm{b}, \mathrm{d})$ AZ31 Mg alloy surfaces after $\mathrm{Cu}$ electrodeposition. (c,d) Cross-sectional images. $(\mathrm{e}, \mathrm{f})$ EDS line analysis at the lines shown in Fig. $\mathrm{c}$ and d. 
On the other hand, in the case of the $\mathrm{Cu}$-prepared sample shown in Fig. 6b, a smooth and dense $\mathrm{Cu}$ surface without defects was obtained on the dense and uniform $\mathrm{Zn}$ layer shown in Fig. 4d. This compact structure was also confirmed from a cross-sectional SEM image shown in Fig. 6d, i.e., a $\mathrm{Cu}$ layer with few defects and a uniform thickness of about $15 \mu \mathrm{m}$ was formed. Defects or voids were not observed at the interface between the $\mathrm{Cu}$ layer and the substrate. An irregular structure of the interface containing pores on the substrate was induced by the acceleration of substrate dissolution due to $\mathrm{Cu}$ pretreatment in the activation process. $\mathrm{Cu}$ deposition in the pores was confirmed by a cross-sectional SEM image, and this may have contributed to the better adhesion strength of the $\mathrm{Cu}$ plating layer as discussed later. In the results of EDS line analysis shown in Fig. 6f, the $\mathrm{Zn}$ signal of the $\mathrm{Cu}$-prepared sample shows a sharp peak and the $\mathrm{Cu}$ signal rapidly increases to a steady value of the $\mathrm{Cu}$ layer. These results confirm that the $\mathrm{Cu}$ pretreatment resulted in formation of a compact and dense $\mathrm{Zn}$ layer on the substrate and enables formation of a $\mathrm{Cu}$ layer with few defects and uniform thickness.

Figure 7 shows the time-transitions of the electrodeposition potential, $E_{\mathrm{ED}}$, on Zn-coated $\mathrm{AZ31} \mathrm{Mg}$ alloy samples prepared with and without $\mathrm{Cu}$ pretreatment during galvanostatic $\mathrm{Cu}$ electrodeposition. In the case of the $\mathrm{Cu}$-prepared sample, $E_{\mathrm{ED}}$ initially decreased and then increased rapidly from a less-noble potential to about -1.0 $\mathrm{V}$ within ca. $110 \mathrm{~s}$ and then increased slowly thereafter. This rapid potential shift at the initial stage indicates that $\mathrm{Cu}$ nucleation proceeded rapidly on the $\mathrm{Zn}$ layer which completely covered the substrate and then $\mathrm{Cu}$ electrodeposition continued on the $\mathrm{Cu}$ deposits. Electrodeposition for the initial $110 \mathrm{~s}$ corresponds to $0.46 \mu \mathrm{m}$ of $\mathrm{Cu}$ layer calculated simply from the $\mathrm{Cu}$ layer thickness of $15 \mu \mathrm{m}$ for 3.6-ks electrodeposition, and this initial thickness seems to be sufficient to cover the substrate shown in Fig. $6 \mathrm{~d}$. From the fact that $\mathrm{Cu}$ was electrodeposited in the pits on the substrate, it is reasonable to assume that some of the $\mathrm{Zn}$ layer dissolved chemically or was removed from the surface to provide an ionic path for $\mathrm{Cu}^{2+}$ to reach these pits for electrodeposition in the initial stage.

In the case of the non-prepared sample, initial $E_{\mathrm{ED}}$ was considerably less noble than that of the $\mathrm{Cu}$-prepared sample. Since $\mathrm{Cu}$ was electrodeposited only on electro-conductive $\mathrm{Zn}$ particles in the initial stage, incomplete $\mathrm{Zn}$ coverage on the non-prepared sample resulted in higher overpotential for $\mathrm{Cu}$ electrodeposition occurring on fewer $\mathrm{Cu}$ particles, and a longer electrodeposition period was necessary for almost complete coverage of the substrate with a $\mathrm{Cu}$ layer. As shown in Fig. 7, $500 \mathrm{~s}$ was needed to cover the substrate with the initial $\mathrm{Cu}$ layer. The thickness of this initial $\mathrm{Cu}$ layer is estimated to be about $2.1 \mu \mathrm{m}$ from the simple calculation described

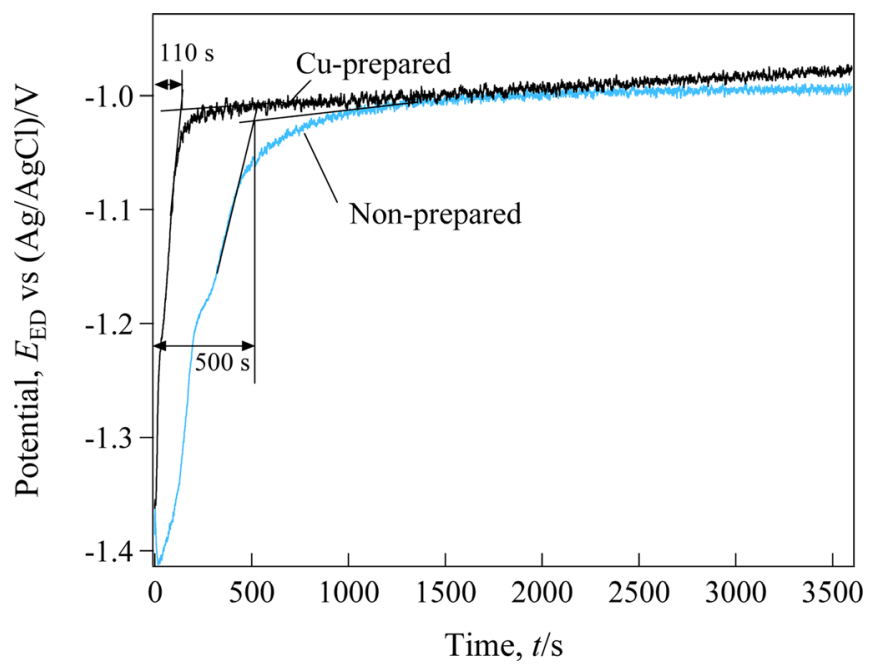

Figure 7. (Color online) Potential-time transitions of non-prepared and $\mathrm{Cu}$ prepared AZ31 Mg alloy samples during galvanostatic electrodeposition of $\mathrm{Cu}$ at $-12 \mathrm{~mA} \mathrm{~cm}^{-2}$.

$\begin{aligned} & \text { Table II. Adhesion strength of the Cu plating layer deposited on } \\
& \text { the } \mathrm{Zn} \text {-coated } \mathrm{AZ31} \mathbf{M g} \text { alloy measured by a pull-off test. Values } \\
& \text { are averaged data of three runs for each condition. }\end{aligned}$
\begin{tabular}{lcc} 
Preparation & Cu-prepared & Non-prepared \\
\hline Adhesion strength (MPa) & 14 & 9
\end{tabular}

above, and this thickness also seems to be comparable to the defective $\mathrm{Cu}$ deposits at the interface shown in Fig. 6c. After 1000 s, $E_{\mathrm{ED}}$ remained at almost the same value as that of the $\mathrm{Cu}$-prepared sample.

Adhesion tests.- Results of test of adhesion strength of the $\mathrm{Cu}$ electroplating layer to the substrate are summarized in Table II. Better adhesion strength was always obtained for the $\mathrm{Cu}$-prepared samples. From the results described in the previous subsections, it is proposed that improvement in adhesion strength due to $\mathrm{Cu}$ pretreatment is provided by dense $\mathrm{Cu}$ seeds on the substrate, which enable dense and compact $\mathrm{Zn}$ deposition followed by $\mathrm{Cu}$ electrodeposition with few defects, due to the defect-less interface structure between the substrate and $\mathrm{Cu}$ layer and also due to the anchor effect provided by irregular dissolution trace of the substrate and complementary $\mathrm{Cu}$ deposition to it. In the case of the non-prepared sample, adhesion was always weak due to a defective interface and less-compact $\mathrm{Cu}$ layer. Figure 8 shows photos of non-prepared and $\mathrm{Cu}$-prepared samples after the pull-off adhesion test. For the non-prepared sample, the $\mathrm{Cu}$ electrodeposited layer was easily detached from the substrate. On the other hand, for the $\mathrm{Cu}$-prepared sample, only a small area of the $\mathrm{Cu}$ layer was detached from the substrate, as shown by an arrow.

The coating process for the AZ31 Mg alloy prepared with or without $\mathrm{Cu}$ pretreatment is schematically represented in Fig. 9. In the case of the non-prepared sample, the preformed corrosion layer partly dissolved in the activation process and a non-uniform $\mathrm{Zn}$ layer was formed on it in the following zincate process. Density of $\mathrm{Zn}$ nucleation was low and $\mathrm{Zn}$ particles became large compared with those of the $\mathrm{Cu}$-prepared sample. In the $\mathrm{Cu}$ electroplating process, $\mathrm{Cu}$ was deposited only on the $\mathrm{Zn}$ particles with low density, resulting in formation of voids or a defective interface between the $\mathrm{Cu}$ layer and the substrate and a defective $\mathrm{Cu}$ layer itself with an uneven surface. On the other hand, for the $\mathrm{Cu}$-prepared sample, dense $\mathrm{Cu}$ deposits were formed in the activation bath containing a small amount of $\mathrm{Cu}^{2+}$ ions. These $\mathrm{Cu}$ deposits acted as catalysts for $\mathrm{Zn}$ deposition in the zincate process, and thus a compact $\mathrm{Zn}$ layer almost completely covered the substrate. $\mathrm{Cu}$ was then electrodeposited on this $\mathrm{Zn}$ layer with few defects at the interface and in the film itself. This plating film also showed improvement in adhesion strength.

In conclusion, $\mathrm{Cu}$ pretreatment applied to the plating process on an AZ31 Mg alloy improves the quality and adhesion strength of the $\mathrm{Cu}$ electroplating layer. It is also expected that the $\mathrm{Cu}$-deposited $\mathrm{Mg}$ alloy can be used as a substrate for $\mathrm{Ni}$ electrodeposition in acidic plating baths to obtain a corrosion-protective $\mathrm{Ni} / \mathrm{Cu}$ coating.

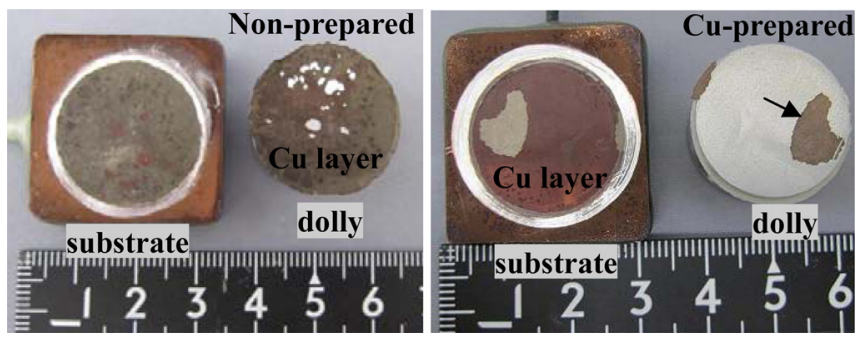

Figure 8. (Color online) Photos of non-prepared and Cu-prepared AZ31 Mg alloy samples after the pull-off adhesion test. 


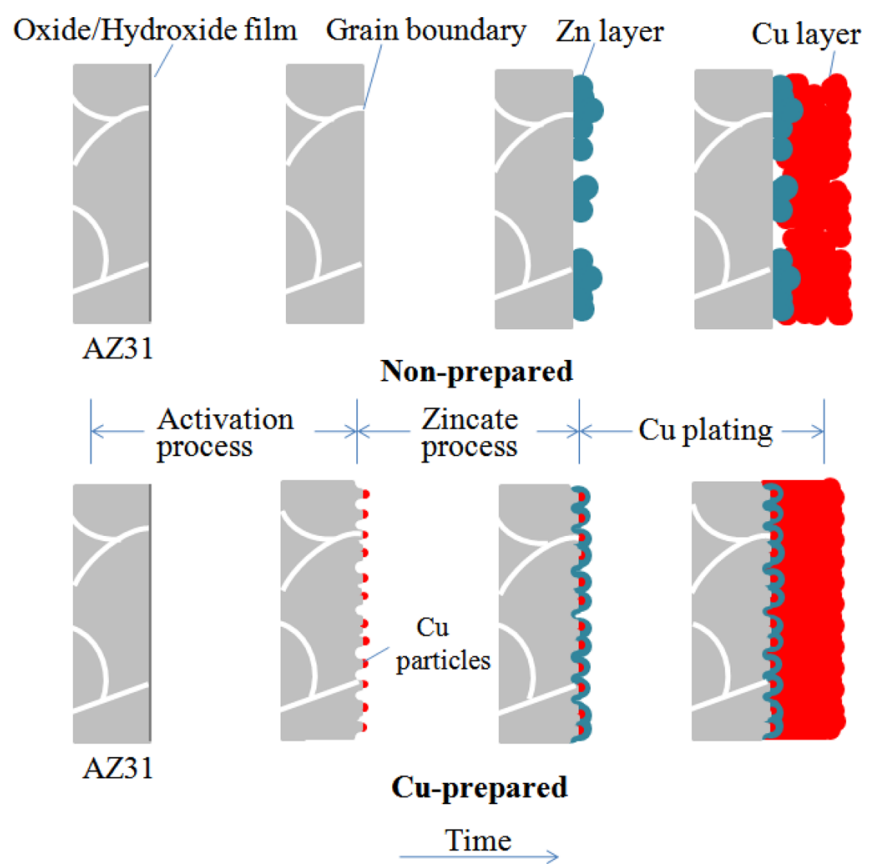

Figure 9. (Color online) Schematic representation of coating formation on non-prepared and $\mathrm{Cu}$-prepared $\mathrm{AZ} 31 \mathrm{Mg}$ alloy samples during the activation, zincate and $\mathrm{Cu}$ electroplating processes.

\section{Conclusions}

In this study, effects of $\mathrm{Cu}^{2+}$ ions in the activation bath on the following zincate process of an AZ31 Mg alloy and on the $\mathrm{Cu}$ electrodeposition were investigated, and the following results were obtained:

1. A small amount of $\mathrm{Cu}$ was deposited uniformly and densely on the $\mathrm{Mg}$ alloy as a substitution reaction of $\mathrm{Mg}$ dissolution in the activation bath containing a low concentration of $\mathrm{Cu}^{2+}$ ions. These $\mathrm{Cu}$ deposits greatly increased the electrochemical activity of the $\mathrm{Mg}$ alloy and promoted $\mathrm{Mg}$ dissolution to provide a uniform substrate suitable for subsequent treatment.

2. $\mathrm{Cu}$ deposition on the $\mathrm{Mg}$ alloy greatly improved the uniformity and density of $\mathrm{Zn}$ deposition in the following zincate process. This effect was provided by $\mathrm{Cu}$ deposits that acted as nucleation sites for $\mathrm{Zn}$ deposition, resulting in the formation of a dense $\mathrm{Zn}$ deposition layer entirely covering the substrate.
3. Nucleation of $\mathrm{Zn}$ deposition in the zincate process was initiated preferentially at the grain boundary on the AZ31 Mg alloy and caused non-uniform $\mathrm{Zn}$ deposition on a sample without $\mathrm{Cu}$ pretreatment. In the case of a Cu-prepared sample, however, further $\mathrm{Zn}$ deposition proceeded on the surface other than the grain boundary and thus the deposition at the grain boundary was insignificant.

4. A smooth dense $\mathrm{Cu}$ layer with few defects was electrodeposited on the $\mathrm{Zn}$-coated AZ31 Mg alloy pretreated with $\mathrm{Cu}$, and the adhesion strength of this $\mathrm{Cu}$ plating layer was considerably improved compared with that of the non-prepared sample.

\section{Acknowledgments}

This work was supported by the Global COE Program (Project No. B01: Catalysis as the Basis for Innovation in Materials Science) from the Ministry of Education, Culture, Sports, Science and Technology, Japan and also supported in part by the Light Metal Educational Foundation.

\section{References}

1. C. A. Huang, T. H. Wang, T. Weirich, and V. Neubert, Electrochim. Acta, $\mathbf{5 3}$ 7235 (2008).

2. H. H. Elsentriecy and K. Azumi, J. Electrochem. Soc., 156, D70 (2009).

3. N. Iranipour, R. A. Khosroshahi, and N. P. Ahmadi, Surf. Coat. Technol., 205, 2281 (2010).

4. W. J. Cheong, B. L. Luan, and D. W. Shoesmith, Corros. Sci., 49, 1777 (2007).

5. H. H. Elsentriecy, K. Azumi, and H. Konno, Electrochim. Acta, 53, 1006 (2007).

6. Z. P. Zhang, G. Yu, Y. J. Ouyang, X. M. He, B. N. Hu, J. Zhang, and Z. J. Wu, Appl. Surf. Sci., 255, 7773 (2009).

7. L. Q. Zhu, W. P. Li, and D. D. Shan, Surf. Coat. Technol., 201, 2768 (2006)

8. J. K. Dennis, M. K. Y. Y. Wan, and S. J. Wake, Trans. Inst. Met. Finish., 63, 74 (1985).

9. J. K. Dennis, M. K. Y. Y. Wan, and S. J. Wake, Trans. Inst. Met. Finish., 63, 81 (1985).

10. A. K. Sharma, M. R. Suresh, H. Bhojraj, H. Narayanamurthy, and R. P. Sahu, Met Finish., 96, 6 (1998).

11. M. J. Zhao, C. Cai, L. Wang, Z. Zhang, and J. Q. Zhang, Surf. Coat. Technol., 205 , 2160 (2010).

12. F. J. Monteiro, M. A. Barbosa, D. R. Gabe, and D. H. Ross, Surf. Coat. Technol., 35, 321 (1988).

13. L. Nanis, Plat. Surf. Finish., 92, 27 (2005).

14. H. Yanagimoto, K. Akamatsu, S. Deki, and K. Gotoh, J. Electrochem. Soc., 150, C260 (2003).

15. K. Azumi, T. Yugiri, T. Kurihara, M. Seo, H. Habazaki, and S. Fujimoto, J. Electrochem. Soc., 150, C461 (2003).

16. S. Zhang, J. D. Baets, M. Vereeken, A. Vervaet, and A. V. Calster, J. Electrochem. Soc., 146, 2870 (1999).

17. R. D. Sun, D. A. Tryk, K. Hashimoto, and A. Hujishima, J. Electrochem. Soc 145, 3378 (1998).

18. K. Azumi, S. Egoshi, S. Kawashima, and Y. Koyama, J. Electrochem. Soc., 154, D220 (2007). 